\title{
Design Consideration of Smart Solar Dryer for Precision Drying
}

\author{
T H BIDYALAKSHMI DEVI* AND YOGESH B KALNAR
}

\begin{abstract}
A sensor based solar dryer was designed to control the drying environment for precision drying of agricultural produce. The system entirely used solar energy utilizing both thermal and electrical effect. Paraffin wax was used for storage of thermal energy whereas solar battery was used to store the electrical energy. Hot air blower was also provided to supply heat when there is less or no solar radiation. Temperature sensors were provided to control the environment of drying chamber. The exhaust fan started operating depending on the set temperature and thus control the drying environment. Load cells were provided below each tray to measure the dry weight. The drying chamber was made of mild steel with glass wool insulation. The capacity of the designed dryer was $10-15 \mathrm{~kg}$ with 6 trays. The designed dryer has target temperature of $55-60^{\circ} \mathrm{C}$.
\end{abstract}

KEYWORDS

Evacuated tube, solar dryer, phase change material, load cells, sensors

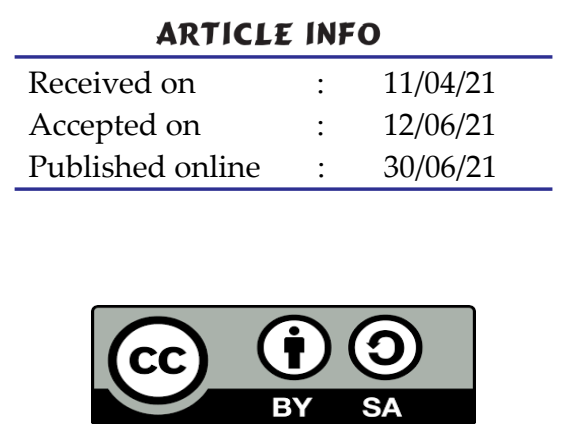

\section{INTRODUCTION}

$\mathrm{D}$ rying is one of the most common post-harvest unit operations for preservation of agricultural products. It helps to prevent the microbial activity caused due to high moisture content and thus, extends the shelf-life of the product (Jairaj et al, 2009). The most common, easy, cheap and traditional method of drying is open sun drying. Open sun drying is carried out at ambient conditions using direct solar radiation. However, it is associated with uncontrolled whether conditions, poor drying quality and large drying time (Sansaniwal et al, 2017). A solar dryer can overcome the limitations of sun drying. On the other hand, solar energy is abundantly available in the country with $5.5 \mathrm{kWh} / \mathrm{m}^{2} /$ day (Musale et al, 2016). Considering the various advantages associated with solar energy and the facts of depleting the conventional energy pool, solar drying would be the best choice that could provide sustainable method of food preservation (Aravindh and Sreekumar, 2015).

Both thermal and electrical power can be harnessed simultaneously from solar energy. Solar photovoltaic has less efficiency than thermal collector in thermal generation. Moreover, thermal and electrical collector are designed for its specific application. Hence, a hybrid system using both electrical and thermal would be more beneficial than singly using thermal generation from solar PV panels. This will be helpful in those areas where availability of grid power is less. Therefore, solar drying provides a viable solution for problems of energy crisis associated with drying and dehydration of agricultural produce. Also, utilizing solar energy in agricultural processing would be a turnover in energy saving as well as in reducing the impact on the environment. Moreover, the government is focusing more on renewable energy sources as the conventional sources has been depleting.
Flat plate type solar collector are commonly used thermal collector used for drying of agricultural produce. This type of dryer has less efficiency than vacuum tube collector due to higher reflection losses. Therefore, use of vacuum tube collector would help in improving the efficiency of drying. On the other hand, use of phase change materials (PCM) for thermal storage medium could help to achieve constant and moderate temperature which is ideal for drying most agricultural produce (Mohanraj and Chandrasekar 2008 and Shalaby et al 2014). This helps in reducing the energy requirement as well as maintain a moderate temperature.

Wise selection of temperature for drying is necessary as agricultural crops are sensitive. However, most of the agricultural products are recommended to dry between $40-60^{\circ} \mathrm{C}$ for safe drying (Kant et al, 2016). On the other hand, control of drying chamber in solar drying for precision drying has not been reported. Use of sensor to control the temperature of the drying environment would not only able to maintain the quality of the product but also would increase the efficiency of the system. In most of the dryer, frequent checking of product condition during the process is necessary to avoid over drying. This can be overcome by providing sensor such as load cell in each tray and indicate the final desire weight. Such control environment of drying chamber using sensors for precision drying has not been reported specially for solar dryers. Keeping the above views, a work has been carried out to design sensor based smart solar dryer for precision drying of agricultural crops.

\section{MATERIALS AND METHODS}

\section{Design of the dryer}

The designed solar dryer was powered entirely by solar energy using both thermal and electrical modules. The ther-

${ }^{1}$ ICAR-Central Institute of Post-Harvest Engineering and Technology, Ludhiana, Punjab-141004, India

*Corresponding author email: bidyala@gmail.com 
mal energy was collected through evacuated tube solar thermal collector whereas electrical energy was obtained through solar photovoltaic panels. Thermal storage was provided through paraffin wax (as phase change materials, PCM) and electrical energy was stored at solar battery. A hot air blower which is powered by electrical energy derived from solar battery was also provided to supply heat when there is less or no radiation. The speed control of the exhaust fan was made in order to control the temperature of the drying chamber. Load cells were provided below each tray to indicate the weight of dry matter and thus prevent overheating. The dryer consisted of drying chamber with sensors and microcontroller arrangement, air heating unit, air handling and distribution unit, thermal storage and power supply. The factors taken for the design of the dryer were moisture content to be removed, total solar energy received in the region and permissible temperature for drying agricultural produce. The designed capacity of the dryer is $10-15 \mathrm{~kg}$.

\section{Determination of design values}

Firstly, the amount of moisture to be removed was calculated. Depending on the mass of the moisture, the quantity of heat required to obtain the desire level of drying was estimated. The total quantity of heat required was determined by the mass of the product to be dried and amount of heat required to vaporize the moisture from the product.

Drying load estimation

a) The amount of moisture to be removed from the product, $\mathrm{m}_{w}(\mathrm{~kg})$ was determined using the following equation (Tonui et al 2014 and Ogheneruona and Yusuf 2011).

$$
m_{w}=m_{p} \frac{\left(m_{i}-m_{f}\right)}{\left(100-m_{f}\right)}
$$

b) The quantity of heat required to remove the moisture content was determined using equation (2).

$Q=m_{p} C_{p} \triangle T_{p}+m_{w} h_{f g}(2)$

$\mathrm{C}_{p}=$ Specific heat of product (Sahay and Singh (2004))

$\mathrm{C}_{w}=$ specific heat of water $(4.18 \mathrm{~kJ} / \mathrm{kgK})$

$\mathrm{C}_{d}=$ specific heat of dry matter $(1.463-1.881 \mathrm{~kJ} / \mathrm{kgK})$

$\Delta \mathrm{T}_{p}=$ change in temperature before and after heating $\left({ }^{\circ} \mathrm{C}\right), \mathrm{t}_{a^{-}}$ $\mathrm{t}_{p}$

Therefore, $\mathrm{C}_{p}=2 \mathrm{~kJ} / \mathrm{kgK}$

$\mathrm{h}_{f g}=$ the latent heat of evaporation in $\mathrm{kJ} / \mathrm{kg}$.

The amount of heat required is the function of temperature and moisture content of crop. The latent heat of vaporization was determined by, (Ogheneruona and Yusuf (2011), Dasin et al (2015))

$\mathrm{h}_{f g}=4.186\left(597-0.56\left(\mathrm{t}_{p r}+273\right)\right)(3)$

where, $\mathrm{t}_{p r}$ is the product temperature $\left[{ }^{\circ} \mathrm{C}\right]$

\section{Design of drying chamber}

The designed drying chamber accommodates six perforated trays in such a way that it provides thin layer drying and at uniform manner. The design factors of drying chamber included its size, number of trays, space between two trays and materials for insulation. The drying chamber was made of mild steel with glass wool insulation of $2.5 \mathrm{~cm}$ to prevent heat loss from the chamber. A hole is provided at the bottom side for the hot air entrance through evacuated tube collector. Parameters like initial moisture content, final moisture content, initial mass of the product, average ambient temperature, solar radiation etc. were considered while designing (Table 1). Materials of construction for the drying chamber were selected based on the technical and economic considerations.

Table 1: Design parameters considered for solar dryer

\begin{tabular}{|c|c|c|}
\hline $\begin{array}{l}\text { Sl. } \\
\text { no. }\end{array}$ & Parameters & $\begin{array}{l}\text { Standard values/ } \\
\text { assumptions/ Determined } \\
\text { values }\end{array}$ \\
\hline 1. & $\begin{array}{l}\text { Initial moisture content } \\
\text { of the product }\left(\mathrm{m}_{i}\right)\end{array}$ & $85-86 \%$ w.b. \\
\hline 2 & $\begin{array}{l}\text { Final moisture content } \\
\text { of ginger }\left(\mathrm{m}_{f}\right)\end{array}$ & $10-13 \%$ w.b. \\
\hline 3. & $\begin{array}{l}\text { Initial mass of the } \\
\text { product to be dried }\left(\mathrm{m}_{p}\right)\end{array}$ & $\begin{array}{l}10-15 \mathrm{~kg} \text {, capacity of the } \\
\text { designed dryer }\end{array}$ \\
\hline 5. & $\begin{array}{l}\text { Initial temperature of } \\
\text { product }\left(t_{p}\right)\end{array}$ & $25^{\circ} \mathrm{C}$ \\
\hline 6. & Specific heat of air $\left(C_{p a}\right)$ & $1.005 \mathrm{~kJ} / \mathrm{kg} \mathrm{K}$ \\
\hline 7 & $\begin{array}{l}\text { Average Ambient } \\
\text { temperature }\left(T_{a}\right)\end{array}$ & $\begin{array}{l}24^{\circ} \mathrm{C} \text { (considering winter } \\
\text { season) }\end{array}$ \\
\hline 8 & Density of air $\left(\rho_{a}\right)$ & $1.225 \mathrm{~kg} / \mathrm{m}^{3}$ \\
\hline
\end{tabular}

\section{Designing and Selection of Solar thermal collector}

Vacuum tube type solar thermal collector was selected as it has less reflection losses and more advantageous than flat plate type thermal collector. Number of tubes are selected based on the temperature required inside the drying chamber, average inclined radiation and manufacturer's values such as optical efficiency, first and second order heat loss coefficient. The thermal output of the system is characterized in terms of the GIR and $\left(\mathrm{T}_{m}-\mathrm{T}_{a}\right)$ (IS:16648, 2017).

$\frac{Q}{\text { Unit Area }}=G I R \times \eta_{0}-a_{1}\left(T_{m}-T_{a}\right)-a_{2}\left(T_{m}-T_{a}\right)^{2}$

Where,

$\mathrm{Q}=$ Rate of energy, Watt

$\mathrm{A}_{P}=$ Aperture area, $\mathrm{m}^{2}$

$\mathrm{GIR}=$ Global inclined radiation, $\mathrm{W} / \mathrm{m}^{2}$

$\mathrm{a}_{1}=$ Temperature dependence first order heat loss coefficient, $\mathrm{W} / \mathrm{m}^{2} \mathrm{~K}$

$\mathrm{a}_{2}=$ Temperature dependence second order heat loss coefficient, $\mathrm{W} / \mathrm{m}^{2} \mathrm{~K}^{2}$

$\mathrm{T}_{m}=$ Mean temperature of the system, ${ }^{\circ} \mathrm{C}$

$\mathrm{T}_{a}=$ Ambient temperature, ${ }^{\circ} \mathrm{C}$

$\eta_{o}=$ Optical efficiency

Air handling and distribution unit

The dryer was operated with forced convection process. The important part of air handling units included of fan that blew hot air to the drying chamber. An exhaust fan was provided at the top side of the dryer.

Thermal storage unit 
Paraffin wax as phase change material was used to store thermal energy during sunshine hours and utilized it during night hours. Considering $70 \%$ of heat energy required for drying is to be supplied during the day time and remaining 30\% energy is to be stored in the thermal storage system for used in nonsunshine hours, the amount of paraffin required for storing the energy can be calculated using the following formula:

Amount of PCM $=\frac{\text { Amount of energy required to be stored }}{\text { Latent heat of storage }}$

\section{Sensor node}

Temperature sensors (NTC-negative temperature coefficient) was provided at the exit of hot air. It has keys, LED display, relay, and operates on DC $12 \mathrm{~V}$ power supply. The controller module has an inbuilt embedded micro-controller, thus not much programming knowledge is required. The heater of the hot air blower was kept $\mathrm{ON}$ when the temperature obtained from the evacuated tube collector was less than the set values. Depending on the set/ programmed conditions of the drying environment, speed of the exhaust fan are controlled after being actuated by the signal received from sensors. Load cells are provided below each tray to measure the mass of dry weight. The change in weight during the drying process is being displayed in the Organic Light Emitting Diode (OLED). The controls are made through microcontroller, programmed through Arduino (Arduino Mega 2560) integrated development environment (IDE) software.

The schematic and designed prototype solar dryer is shown in Figure 1 and Figure 2, respectively

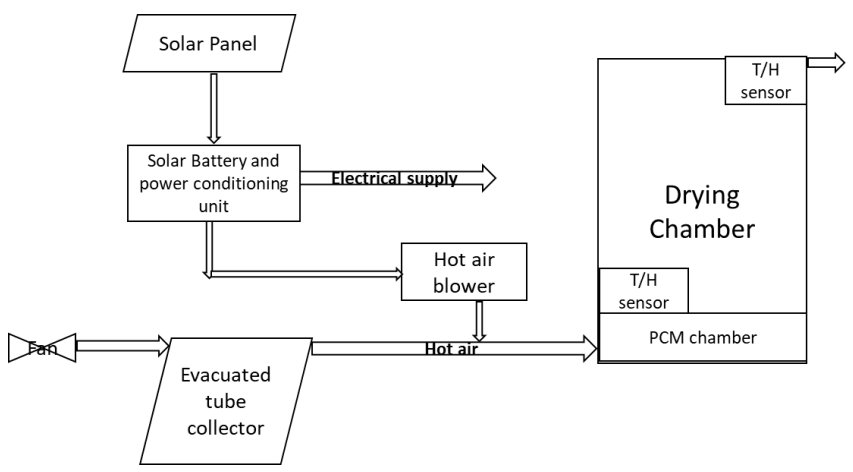

Fig. 1: Schematic diagram of the developed solar dryer

\section{Performance evaluation of the dryer}

The dryer was evaluated for following characteristics

\section{System Efficiency}

The system efficiency can be defined as the ratio of energy required to evaporate the water and sensible heat require to raise the temperature of the product to the useful energy gained from solar collector (Tonui et al, 2014).

$$
\eta_{\text {dryer }}=\frac{m_{p} C_{p} \triangle T_{p}+m_{w} h_{f g}}{Q_{a}}
$$

Where, $\mathrm{Q}_{a}=$ total energy received from the evacuated tube solar thermal collector.

\section{Specific moisture extraction rate (SMER}

SMER is one of the important performance indicators of a drying system which is defined as the amount of water evaporated per unit energy consumption in $\mathrm{kg} / \mathrm{kWh}$ as given by (Prakash and Kumar (2017) ).

$$
S M E R=\frac{\text { Mass of water removed, } \mathrm{kg}}{\text { Total energy consumption, } \mathrm{kwh}}
$$

The reciprocal of SMER gives the Specific energy consumption (SEC).

\section{RESULTS AND DISCUSSION}

The proposed designed of the solar dryer has capacity of 10$15 \mathrm{~kg}$. The schematic diagram of the developed solar dryer included dryer with PCM chamber, evacuated tube thermal collector, fan, Solar Photovoltaic panel, solar battery with power conditioning unit, hot air blower etc. (Figure 1 ). The dryer is entirely operated by solar energy including both thermal and electrical storage. The thermal energy is obtained from Evacuated tube thermal collector whereas photovoltaic panels provided the electrical energy required for fans and sensors. A hot air blower is also provided to be used when there is less or no radiation. The hot air reached the drying chamber through PCM box. Temperature sensor is provided at the exhaust. Depending on the set desire temperature at the exhaust side, the fan speed actuated through microcontroller through temperature sensor. Thus the temperature inside the chamber is being controlled. Load cells are provided below each tray to indicate the mass of dried product. Hence, the dried product can be removed in time and thus preventing overheating of the product.

The drying chamber was made of mild steel with glass wool insulation of $2.5 \mathrm{~cm}$. The dryer has capacity of 10 to $15 \mathrm{~kg}$ with 6 trays. The targeted temperature to be attained inside the drying chamber was kept as $55-65^{\circ} \mathrm{C}$. The proposed dimensions of the designed dryer are $(77 \times 65 \times 96) \mathrm{cm}$ at front and $(77 \times 65 \times 121) \mathrm{cm}$ at back side. The slope provided at back side would enable easy flow of the exhaust air.

\section{CONCLUSIONS}

A solar dryer was designed to control the drying environment using sensors for precision drying keeping in view of huge potential of solar energy, its availability and environmentally friendly. The designed dryer is solely operated with solar power utilizing both thermal and electrical energy. Used of sensor for controlling drying chamber enable to achieve precision drying. Application of solar energy could provide sustainable approach of agricultural processing. This proposed design low capacity solar dryer will be economical to use by the farmers to maintain the quality of the dry product. Also, it can be scale up for entrepreneur and industrial applications. 


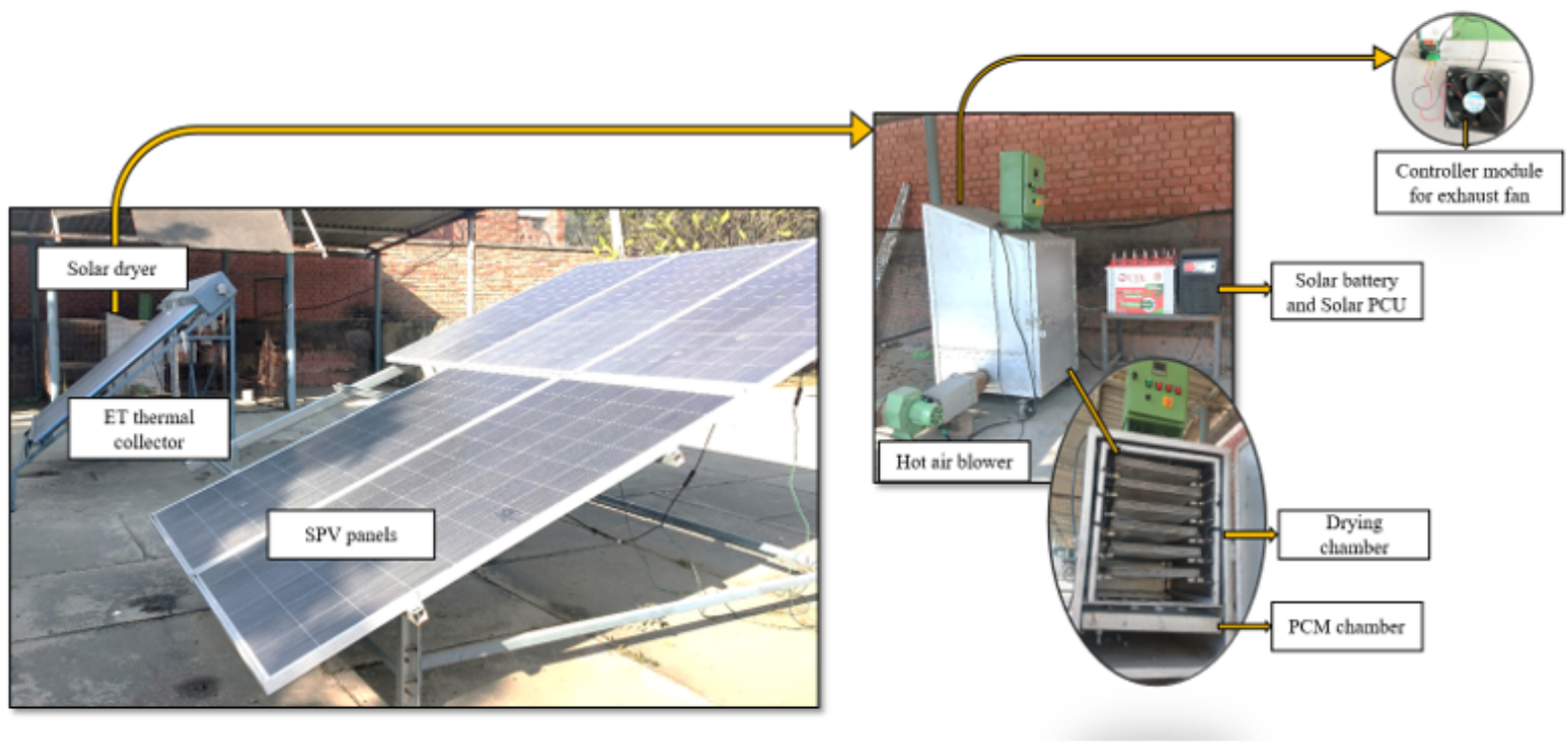

Fig. 2: Developedsystem of the solar dryer

\section{REFERENCES}

Aravindh M and Sreekumar A. 2015. Solar Drying-A Sustainable Way of Food Processing. Energy Sustainability through Green Energy 26:27-46.

Dasin DY, Ny G and Kingsley OC. 2015. Experimental Investigations of the performance of passive solar food dryer tested in Yola Nigeria. International Journal of Energy Engineering 5(1):9-15.

IS:16648 2017. IS 16648 (Part 5). Concentrated solar thermal- Part 5 Test Methods.

Jairaj KS, Singh SP and Srikant K. 2009. A review of solar dryers developed for grape drying. Solar Energy 83(9):1698-1712. url: https://dx.doi.org/10.1016/j.solener.2009.06.008. doi: 10.1016/j. solener.2009.06.008

Kant K, Shukla A, Sharma A, Kumar A and Jain A 2016. Thermal energy storage based solar drying systems: A review. url: https://dx.doi.org/10.1016/j.ifset.2016.01.007. doi: 10.1016/ j.ifset.2016.01.007

Mohanraj M and Chandrasekar P. 2008. Drying of copra in a forced convection solar drier. Biosystems Engineering 99(4):604607. url: https://dx.doi.org/10.1016/j.biosystemseng.2007.12. 004. doi: 10.1016/j.biosystemseng.2007.12.004

Musale Y, Patil S, Kalkarni CB and A. 2016. Recent Developments in Solar Refrigeration Technology-A Review. International Jour- nal of Current Engineering and Technology 4:95-98.

Ogheneruona DE and Yusuf MOL. 2011. Design and fabrication of a direct natural convection solar dryer for Tapioca. Leonardo Electronic Journal of Practices and Technologies 18:95-104.

Prakash O and Kumar A 2017. Solar Drying Technology Concept, Design, Testing, Modeling, Economics, and Environment. Green Energy and Technology (Singapore: Springer Nature).

Sahay KM and Singh KK 2004. Unit Operations of Agricultural processing (Delhi: Vikas Publishing House Private Limited), 9-11.

Sansaniwal SK, Kumar M and Rajneesh VK. 2017. Investigation of Indirect Solar Drying of Ginger Rhizomes (Zingiber Officinale): A Comparative Study. Journal of Engineering Science and Technology 12(7):1956-1971.

Shalaby SM, Bek MA and El-Sebaii AA. 2014. Solar dryers with PCM as energy storage medium: A review. Renewable and Sustainable Energy Reviews 33:110-116. url: https://dx.doi.org/10.1016/ j.rser.2014.01.073. doi: 10.1016/j.rser.2014.01.073

Tonui KS, Mutai EBK, Mutuli DA, Mbuge DO and Too KV. 2014. Design and Evaluation of Solar Grain Dryer with a Back-up Heater. Research Journal of Applied Sciences, Engineering and Technology 7(15):3036-3043. url: https://dx.doi.org/10.19026/ rjaset.7.639. doi: 10.19026/rjaset.7.639 